\title{
Development of novel thiolated carboxymethyl-gellan gum as potential mucoadhesive polymer: Application of DoE
}

\author{
Mahesh P. More ${ }^{1}$, Manoj S. Bhamare ${ }^{1}$, Chetan J. Bhavsar ${ }^{3}$, Pravin O. Patil ${ }^{2}$ and Prashant K. Deshmukh ${ }^{1 *}$ \\ ${ }^{1}$ Post Graduate Department of Pharmaceutics, H. R. Patel Institute of Pharmaceutical Education and Research, Karwand Naka, India \\ ${ }^{2}$ Department of Pharmaceutical Chemistry, H. R. Patel Institute of Pharmaceutical Education and Research, Karwand Naka, India \\ ${ }^{3}$ Department of Pharmacognosy, H. R. Patel Institute of Pharmaceutical Education and Research, Karwand Naka, India
}

\begin{abstract}
The objective of the present investigation was to synthesize soluble carboxymethyl-gellan gum (CMG) from gellan gum (GG) using statistical experimental design (DoE) strategy. Experimental design can potentially calculate the optimum reaction condition required to obtain response i.e. degree of substitution (DS) of CMG, which was statistically assessed. The effect of two process factors, namely concentration of monochoroacetic acid and water:isopropanol ratio on DS was investigated. Another objective of present study was to improve the mucoadhesive strength of optimized CMG by its covalent attachment with thiol moieties so as to get thiolated carboxymethyl-gellan gum (TCG). Synthesized CMG and TCG were characterized by FT-IR, DSC and NMR. Polymer compacts of TCG exhibited 3.73 fold greater adhesive strength on goat intestinal mucosa as compared with bare GG. In accordance with the promising results obtained; synthesized TCG can be considered as potential modified polymer for further drug delivery applications, especially mucoadhesive systems.
\end{abstract}

\section{Introduction}

Mucoadhesion can be defined as the ability of biological or synthetic macromolecules to adhere to the mucosal tissues [1]. Over the last few years thiolated polymers or so-called thiomers appeared as a promising excipient for the delivery of drugs including peptides [2]. It could be concluded that polymers with thiol groups provide better mucoadhesive properties than polymers generally considered to be mucoadhesive [3]. The enhancement of mucoadhesion can be explained by the formation of covalent bonds between the polymer and the mucus layer which are stronger enough than non-covalent bonds. These thiolated polymers are supposed to interact with cysteine rich sub domains of mucus glycoproteins through disulfide exchange reactions and/or simple oxidation process [4].

Mucoadhesive drug delivery system is beneficial over other conventional delivery approaches, mucodhesive property enhances the residence time of drug at the site of application probably due to intimate contact with absorption site, ultimately enhances bioavailability of therapeutic agents resulting from the avoidance of some of the natural defense mechanism of human body [5]. Till date, various synthetic approaches utilizing thiol moieties has been already verified on various polymers, such as chitosan, gellan gum (GG), poly(acrylic acid), alginate, pectin, etc [6-11].

Gellan gum (GG) is the generic name given to extracellular polysaccharide obtained from bacterium Pseudomonas elodea which was isolated from the elodea plant tissues. GG was previously referred as codenames of S-60 and PS-60 but US-FDA approved the GG, in 1992 as a food additive [12]. Chemically, it is a linear anionic polymer with a tetrasaccharide repeating units comprising of one a $\alpha$-L-rhamnose, one $\beta$-D-glucuronic acid and two $\beta$-D-glucose residues in molar ratio of $2: 1: 1[13,14]$. The native form of GG contains two acyl substituents viz. O-acetyl and O-l-glyceryl on the 3-linked glucose [15]. Garcia et al. reported in 2011 the relative conversion of native
GG into low-acyl or highly deacetylated GG can be done by alkaline treatment. GG possess an inherent property of forming a transparent gel in presence of multivalent cations (such as $\mathrm{Ca}^{+2}$ and $\mathrm{Al}^{+3}$ ) which is resistant to heat and acids $[12,16]$. The GG has been explored for a wide range of applications in food and pharmaceutical industries such as, emulsifier, stabilizer, binder, gelling agent, lubricant, film former and thickening agent because of its physical and functional properties [17]. GG also modifies the release rate of active ingredients from tablets and capsules [18]. The GG gel confirmed increased bioavailability of theophylline which was 4-5 folds in rats and 3 fold in rabbits compared to commercial sustained release liquid dosage forms [19].

As GG is an anionic heteropolysaccharide, the interaction between the carboxylic group of GG and cations plays an important role in the sol-gel transformation of GG [20,21]. In carboxymethylation of GG, the reaction generally occurs through combination of two effects, i.e. through increase in charge on cellulosic side chain and due to destruction of hydrogen bonds between cellulose chains [22]. Carboxymethylation is an intermediate steps from various schemes used for functionalization of natural polymers [23] and to develop new biomaterial with very promising application. This reaction is reported for various natural polymers, such as cellulose, starch, chitosan, galactomannan, xylan, xanthan gum and gum kondagu, as starting materials [24-31]. The derivatives were polyelectrolyte's and can be utilized in a various field such as chemical, pharmaceutical,

Correspondence to: Prashant Krishanrao Deshmukh, Post Graduate Department of Pharmaceutics, H. R. Patel Institute of Pharmaceutical Education and Research, Karwand Naka, Shirpur, Dist- Dhule 425405, India, Tel: +91 9923434565; E-mail: pkdesh@rediffmail.com

Key words: gellan gum, carboxymethylation, optimization, thiolation, experimental design

Received: April 03, 2017; Accepted: May 02, 2017; Published: May 05, 2017 
food and cosmetic industries [32]. To date, carboxymethylation of GG and evaluation of carboxymethylated-GG (CMG) is reported [22,31]. No report is available in literature about statistical optimization CMG synthesis process.

The product obtained after carboxymethylation differs in the degree of substitution depending on the reaction condition and concentration of reactants. To get products with highest degree of substitution, the reaction conditions and concentration of reactants needs to be optimized. In the present investigation, statistical design of experiments (DoE) was used which is generally employed for obtaining the largest possible amount of information about a system with the smallest number of experiments [33]. The classical method of chemical synthesis optimization involves varying one parameter at a time by keeping others constant; however this method is ineffective, as it fails to understand relationships between the variables and the responses [34,35]. By using DoE, degree of substitution (DS) was optimized in synthesis of $\mathrm{N}$-carboxybutylchitosan and 1-allyloxy-2-hydroxy-propylstarch previously [36,37].

In present work, we report use of DoE for carboxymethylation process optimization of GG. In addition to this and to the best of our knowledge, we are the first to report thiolation of optimized CMG polymer. The carboxymethylation of GG was performed by adopting Williamson's synthesis. The objectives of present study were to optimize DS of CMG using DoE and to synthesize and characterize TCG for its potential mucoadhesive properties. In thiolation process, covalent attachment of sulfhydryl compound was done so as to get CMG thioglycolic acid conjugate (TCG). The mucoadhesive strenth of TCG and physicochemical properties with special emphasis on disintegration studies and swelling behavior are reported.

\section{Materials and methods}

\section{Materials}

Gellan gum (kelcogel CG-LA) was generously gifted by A Huber Company C.P. Kelco. (Mumbai, India). Monochoroacetic acid (MCA) and Sodium hydroxide were purchased from Hi-Media Lab. Private Ltd. and Loba Chemie Pvt. Ltd. (Mumbai, India) respectively. Thioglycolic acid and Isopropyl alcohol (IPA) were procured from Merck Specialties Pvt. Ltd. (Mumbai, India). All other chemicals used were of analytical grade and used as received.

\section{Synthesis of carboxymethylated gellan gum (CMG)}

CMG was synthesized using the method as previously described in the literature with slight modification [38]. The method in brief involves addition of $10 \mathrm{~g}$ chitosan and $13.5 \mathrm{~g}$ sodium hydroxide in 100 $\mathrm{mL}$ solvent (varying water:IPA ratio ), allowed to swell and alkalized for $2 \mathrm{~h}$ at $50^{\circ} \mathrm{C}$. Then MCA (varying concentration) dissolved in $20 \mathrm{~mL}$ IPA was added drop-wise for $30 \mathrm{~min}$. After continue stirring for an additional $4 \mathrm{~h}$ at $55^{\circ} \mathrm{C}, 200 \mathrm{~mL}$ of $70 \%$ ethyl alcohol was added. The solid product then obtained was filtered, rinsed with $70 \%$ ethyl alcohol to desalt and dewater, and finally dried at $55^{\circ} \mathrm{C}$.

\section{Experimental design}

Synthesis of CM-gellan gum was carried out employing a general factorial design. The concentration of MCA and water:IPA ratio were selected as formulation variables on the basis of previous trials. All other formulation and processing variables were kept invariant throughout the study. Table 1a summarizes an account of the 9 experimental runs studied along with optimized batch (OCMG), their factor combination and the translation of the coded levels to the
Table 1a. Composition of factorial batches using $3^{2}$ factorial design.

\begin{tabular}{|c|c|c|c|c|}
\hline Batch code & Run & MCA (gm) & $\begin{array}{c}\text { Water : IP } \\
\text { Ratio }\end{array}$ & Response DS \\
\hline $\mathbf{C M G}_{\mathbf{1}}$ & 1 & 1.5 & $1: 5$ & 0.298 \\
\hline $\mathbf{C M G}_{\mathbf{2}}$ & 2 & 2 & $1: 3$ & 0.274 \\
\hline $\mathbf{C M G}_{\mathbf{3}}$ & 3 & 1 & $1: 4$ & 0.294 \\
\hline $\mathbf{C M G}_{\mathbf{4}}$ & 4 & 1.5 & $1: 4$ & 0.328 \\
\hline $\mathbf{C M G}_{\mathbf{5}}$ & 5 & 1 & $1: 5$ & 0.288 \\
\hline $\mathbf{C M G}_{\mathbf{6}}$ & 6 & 1 & $1: 3$ & 0.145 \\
\hline $\mathbf{C M G}_{\mathbf{7}}$ & 7 & 2 & $1: 4$ & 0.373 \\
\hline $\mathbf{C M G}_{\mathbf{8}}$ & 8 & 2 & $1: 5$ & 0.334 \\
\hline $\mathbf{C M G}_{\mathbf{9}}$ & 9 & 1.5 & $1: 3$ & 0.265 \\
\hline $\mathbf{O C M G}$ & 10 & 2 & $1: 4.14$ & 0.363 \\
\hline
\end{tabular}

experimental units employed during the study. The DS was considered as response variable. The DoE and statistical analysis of data were done using the Design Expert software (Version 8.0.4, Stat-Ease Inc., USA).

\section{Synthesis of thiolated CMG (TCG)}

The TCG was synthesized by the esterification of CMG with thioglycolic acid in the presence of hydrochloric acid. The reaction was carried out with 2 moles of thioglycolic acid for every 1 mole of hydroxyl group in CMG [39]. CMG (13 g) was dissolved in $57 \mathrm{~mL}$ of water and $6.7 \mathrm{~g}$ of $80 \%$ thioglycolic acid was added along with $1.62 \mathrm{~mL}$ of $7 \mathrm{~N} \mathrm{HCl}$. The reacting mixture was allowed to react for $150 \mathrm{~min}$ at $80^{\circ} \mathrm{C}$. Finally, the mixture was poured in $400 \mathrm{~mL}$ of methanol. White precipitate of TCG thus obtained was washed twice with methanol and dried at room temperature.

\section{Characterizations of polymers}

Fourier transforms infra-red spectroscopy (FT-IR): GG, CMG and TCG were characterized using Fourier transform infrared (FTIR) spectrophotometer (Schimadzu). The samples were blended with solid $\mathrm{KBr}$ powder and about $40 \mathrm{mg}$ of the blend was made into a pellet. The $\mathrm{KBr}$ pellet was dried and subjected for FT-IR spectrophotometric analysis. Transmittance was recorded at wave numbers between 4000 to $400 \mathrm{~cm}^{-1}$.

Differential scanning calorimetry (DSC): DSC thermograms of GG, CMG and TCG were recorded using a differential scanning calorimeter (DSC, Mettler, Toledo, Switzerland). About $2 \mathrm{mg}$ of sample was crimped in a standard aluminum pan and heated in a temperature range of 40 $350^{\circ} \mathrm{C}$ at a heating rate of $10^{\circ} \mathrm{C}$ per min under nitrogen atmosphere.

${ }^{1}$ H NMR: Nuclear Magnetic Resonance spectroscopy of the GG, CMG and TCG was carried out using NMR spectrometer (Bruker Avance III, $400 \mathrm{MHz}$ ). The GG, CMG and TCG in powder form were scanned from 1 to $10 \mathrm{ppm}$ range.

Determination of degree of substitution (DS): The degree of substitution of CMG was determined using titrimetry according to a previously reported method in the literature [40]. In brief, CMG (1.5 g) was dispersed in $50 \mathrm{~mL}$ of $2 \mathrm{M} \mathrm{HCl}$ (70\% methanol as solvent), and the suspension was kept under continuous magnetic stirring for $2 \mathrm{~h}$. During this process, the CMG, which was in sodium salt form (Na-CMG) was converted to the hydrogen form (H-CMG). Obtained H-CMG was washed with $95 \%(\mathrm{v} / \mathrm{v})$ ethanol until free of chlorine (tested by $0.1 \mathrm{M}$ silver nitrate solution). The dispersion was filtered, and dried in an oven at $60^{\circ} \mathrm{C}$ for $2 \mathrm{~h}$. Dried H-CMG $(0.5 \mathrm{~g})$ was dissolved in $50 \mathrm{~mL}$ of standardized $0.1 \mathrm{M} \mathrm{NaOH}$ solution and stirred for $2 \mathrm{~h}$. Then the excess of $\mathrm{NaOH}$ was back titrated with standardized $0.1 \mathrm{M} \mathrm{HCl}$ solution using phenolphthalein as an indicator. The DS was determined using the following calculation: 


$$
\begin{aligned}
W_{A} & =\frac{C_{\mathrm{NaOH}} V_{\mathrm{NaOH}}-C_{\mathrm{HCl}} V_{\mathrm{HCl}}}{m} \mathrm{CH}_{2} \mathrm{COOH} V_{\mathrm{NaOH}} \\
D S & =\frac{162 W_{A}}{4900-59 W_{A}}
\end{aligned}
$$

Where, $\mathrm{C}_{\mathrm{NaOH}}$ and $\mathrm{C}_{\mathrm{HCI}}$ are the molar concentration of standard $\mathrm{NaOH}$ and $\mathrm{HCl}$ solutions, $W_{A}$ is the mass fraction of $\mathrm{CH}_{2} \mathrm{COOH}$ (acetyl group), $59(\mathrm{~g} / \mathrm{mol})$ is the molar mass of $\mathrm{CH}_{2} \mathrm{COOH}, \mathrm{V}_{2 a O H}$ is the volume of $\mathrm{NaOH}(50.00 \mathrm{~mL})$ and $V_{\mathrm{HCI}}$ is the volume of $\mathrm{HCl}$ used for the titration of the excess of $\mathrm{NaOH}$, and $\mathrm{m}(\mathrm{g})$ is the weight of polymer taken, $162 \mathrm{~g} / \mathrm{mol}$ is the molar mass of the anhydroglucose unit

Viscosity: Viscosities of GG and CMG solutions were measured by LVDV-II + Pro viscometer (Brookfield, Eng.) using small sample adaptor with spindle number 0 at 5-50 rpm shear rate.

Determination of thiol group content: About 2 gm of TCG was weighed and placed in iodine flask. To this, $50 \mathrm{~mL}$ of n-butanol was added and shaken vigorously, finally titrated with $0.1 \mathrm{~N}$ cupric n-butyl phthalate solution by addition of $0.5 \mathrm{~mL}$ portions near the end point. The solution was darkened during the titration but became clear near the end point, which was identified by the persistence of blue-green color of the reagents [41].

$$
\% S H=\frac{(V 1-V 2) \times N_{1} \times 33.07 \times 100}{W \times 1000}
$$

Where, $\mathrm{V} 1=$ volume of $0.1 \mathrm{~N}$ cupric $\mathrm{n}$-butyl phthalate for sample

$\mathrm{V} 2=$ volume of $0.1 \mathrm{~N}$ cupric n-butyl phthalate for blank

$\mathrm{N} 1$ = normality of cupric reagents

$\mathrm{M}=$ molecular weight of sample and

$\mathrm{W}=$ weight $(\mathrm{g})$ of sample.

Swelling and gel fraction studies: Swelling and gel fraction studies were carried out on the basis of a previously reported literature [42]. Briefly, 0.1 g GG and TCG was weighed and placed in small dishes, which were carefully inserted into the glass flasks. A volume of $60 \mathrm{~mL}$ distilled water was slowly poured into each glass flask. The samples were allowed to soak for $2 \mathrm{~h}$ at room temperature, after that the excess solution was carefully removed, and the remaining gelled samples in the glass bottles were weighed. The gelled samples were lyophilized for three days and then weighed again. The swelling ratio and percentage of gel fraction were calculated using Equations, (4) and (5).

$$
\begin{gathered}
\text { Percentage gel fraction }=\frac{W_{\text {gel }}}{W_{\text {solid }}} \times 100 \\
\text { Percentage gel fraction }=\frac{W_{\text {gel }}}{W_{\text {solid }}} \times 100
\end{gathered}
$$

Where, $\mathrm{W}_{\text {water }}$ is the weight of the sample after $2 \mathrm{~h}$ soaking, $\mathrm{W}_{\text {gel }}$ is the weight of the sample after lyophilization, and $\mathrm{W}_{\text {solid }}$ is the initial weight of the sample.

Evaluation of mucoadhesive potential of GG and Thiolated CG: Compacts of powdered GG and TCG (100 mg) were prepared by direct compression method employing a $12 \mathrm{ST}$ tablet punching machine (Mini Press II - MT Karnavati Engineering Limited, Andheri (E) Mumbai, India) using $11 \mathrm{~mm}$ diameter of pressure 06 tons for $40 \mathrm{~s}$. The mucoadhesive potential of polymer compacts (GG and TCG) was evaluated using texture analyzer (CT3, Texture Analyzer, Brookfield, USA). The analyzer was equipped with a $5 \mathrm{~kg}$ load cell. The polymer compacts were attached to the upper probe, while a goat intestinal mucosa was attached to the lower probe as the model membrane. During the measurement, the probe was lowered at a rate of $0.1 \mathrm{~mm} / \mathrm{s}$ until a contact with the model membrane at a constant force of $3 \mathrm{~N}$ was obtained. The force was maintained for 10 second and the upper probe was moved upwards at a rate of $0.1 \mathrm{~mm} / \mathrm{s}$. The force required to detach the polymer compact from membrane was considered as index of mucoadhesive potential [43].

Swelling behavior: The water-absorbing capacity of gum (TCG and GG) was determined by a gravimetric method. Sixty milligrams of each of the TCG and GG were compressed (Mini Press II - MT Karnavati Engineering Limited, Andheri (E) Mumbai-72, India) to $11 \mathrm{~mm}$ diameter flat-faced tablets. The compaction pressure was kept constant during preparation of all tablets. Test tablets were fixed to a needle and placed in a beaker containing $100 \mathrm{~mL}$ phosphate buffer $\mathrm{pH}$ 6.8 at $37.5^{\circ} \mathrm{C}$. At scheduled time intervals, the swollen test tablets were taken out of the incubation medium, excess water was removed and the water uptake was determined gravimetrically [1].

Disintegration studies: The stability of test discs as described above were analyzed in $0.1 \mathrm{M}$, phosphate buffer $\mathrm{pH} 6.8$ using disintegration test apparatus according to the European Pharmacopeia at an oscillating frequency of $0.5 \mathrm{~s}^{-1}$ and $37^{\circ} \mathrm{C}$.

\section{Result and discussion}

\section{Synthesis of CMG}

The carboxymethylation of GG employed the Williamson's ether synthesis process, which consist of a consecutive two-step reaction [44]. The main reaction proceeds in presence of strong base such as sodium hydroxide that first reacts and deprotonates the hydroxyl groups in GG to form alkoxides group that increasing their nucleophilicity. The carboxymethyl groups are then formed in a $\mathrm{SN}_{2}$ reaction between the gellan alkoxides and monochoroacetic acid. The overall reaction is given by,

$$
\begin{aligned}
& \mathrm{GG}-\mathrm{OH}+\mathrm{NaOH} \rightarrow \mathrm{GG}-\mathrm{ONa}+\mathrm{H}_{2} \mathrm{O} \\
& \mathrm{GG}-\mathrm{ONa}+\mathrm{ClCH}_{2} \mathrm{COOH} \rightarrow \mathrm{GG}-\mathrm{OCH}_{2} \mathrm{COONa}+\mathrm{NaCl}
\end{aligned}
$$

A side reaction, shown below, takes place simultaneously in both liquid bulk and gum phase resulting in the formation of sodium glycolate from sodium monochloroacetate and sodium hydroxide [45]. Thus, the optimization study on the carboxymethylation process was carried out to improve substitution of the carboxymethyl groups in GG, while minimizing the undesired side reaction.

$$
\mathrm{NaOH}+\mathrm{ClCH}_{2} \mathrm{COONa} \rightarrow \mathrm{HOCH}_{2} \mathrm{COONa}+\mathrm{NaCl}
$$

\section{Experimental design}

It has been observed that varying process factors such as the weight of MCA and the water: IPA ratio strongly influence the efficiency of the carboxymethylation process when other parameters were kept constant. Using the general factorial design, the influences of these process factors towards the dependent variable (DS) of the CMG was studied. The process factors and result of response for nine runs along with optimized batch (OCMG) are summarized in Table 1a.

\section{Synthesis of TCG}

The covalent attachment of CMG to thioglycolic acid was achieved by ester bond formation between hydroxyl group of glucuronic acid moieties of CMG and carboxyl group of thioglycolic acid. After complete drying, product appeared as off-yellow odorless powder, which was 
soluble in water. The average yield of this synthesis amounted to $48 \%$ of the utilized amount of CMG. Precipitation with methanol from an aqueous solution and subsequent washing by keeping the precipitate over night was found to be sufficient purification method for TCG.

\section{Fourier transforms infra-red spectroscopy (FT-IR)}

Primary confirmation accessed by characterizing by FTIR spectrophotometer and spectra of GG, CMG and TCG shown in Figure 1. The spectra of GG shows broad absorption band at $3231 \mathrm{~cm}^{-1}$ due to O-H stretching of $\mathrm{COOH}$ group, a peak at $2922 \mathrm{~cm}^{-1}$ is due to $\mathrm{C}-\mathrm{H}$ stretching of alkane. Peaks appearing at 1611 and $1422 \mathrm{~cm}^{-1}$ can be attributed to $\mathrm{C}=\mathrm{O}$ stretching of carboxylic acid of glucuronic acid. The spectra of CMG shows a broad absorption band at $3413 \mathrm{~cm}^{-1}$ due to O-H stretching of alcohols, a peak at $2925 \mathrm{~cm}^{-1}$ is due to C-H stretching of alkane. The peaks appearing at 1610,1420 and $1070 \mathrm{~cm}^{-1}$ can be ascribed to $\mathrm{C}-\mathrm{O}$ stretching, $\mathrm{COO}-$ of carboxylate anion and $\mathrm{C}-\mathrm{O}$ stretching of primary alcohols respectively. Whereas the FTIR spectra of TCG shows a weak peak at $2359 \mathrm{~cm}^{-1}$ which is due to presence of the $\mathrm{SH}$ group.

\section{Differential scanning calorimetry (DSC)}

Thermal behavior of synthesized GG, CMG, and TCG were performed and illustrated in Figure 2. The DSC curve of GG shows two endothermic peak one at $286.76^{\circ} \mathrm{C}$ with heat of fusion $-352.49 \mathrm{~J} / \mathrm{g}$ and other peak at $289.25^{\circ} \mathrm{C}$ with heat of fusion $-215.43 \mathrm{~J} / \mathrm{g}$. The DSC thermogram of CMG shows endothermic peak at $257.5^{\circ} \mathrm{C}$ with heat of fusion $7.253 \mathrm{~J} / \mathrm{g}$. The DSC thermograms of TCG shows endothermic peak at $154.33^{\circ} \mathrm{C}$ with heat of fusion $-209.51 \mathrm{~J} / \mathrm{g}$. Thus, a decrease in endothermic transition temperature and heat of fusion was observed in CMG and TCG.

\section{${ }^{1}$ H NMR}

In order to explore possible modification of GG, CMG and TCG, ${ }^{1} \mathrm{H}$ NMR spectra of GG, CMG and TCG was compared (Figure 3). NMR spectra of GG showed four characteristic peaks corresponding to - $\mathrm{CH}$ of rhamnose (d $5.29 \mathrm{ppm}),-\mathrm{CH}$ of glucuronic acid (d $5.11 \mathrm{ppm})$, $-\mathrm{CH}$ of glucose (d $4.88 \mathrm{ppm})$ and $-\mathrm{CH}_{3}$ of rhamnose (d $\left.1.45 \mathrm{ppm}\right)$. The characteristic proton signals of $\mathrm{CM}$-gellan appeared in the range of 4.0-4.1 ppm, indicating the conjugation of carboxymethyl groups to gellan moiety. The NMR spectra of thiolated carboxymethyl gellan showed singlet peaks near 3.6, 3.5, 3.4 and 3.29 ppm which can be correlated to the presence of sulfhydryl protons [46].

\section{Optimization of DS}

The DS of CMG was determined using titrimetric method. In the carboxymethylation of GG, the effect of concentration of MCA and water: IPA ratio was investigated for optimization of DS using factorial design (Table 1a). The results of response generated were fitted into polynomial models and ANOVA test was applied to estimate their significance. The results of this analysis revealed that DS was fitted best into the response surface quadratic model.

The polynomial models for response DS (Y) can be represented by equations 9 .

$$
\mathrm{Y}=0.34+0.04 \mathrm{~A}+0.039 \text { B-0.021 A.B. }-0.012 \mathrm{~A}^{2}-0.064 \mathrm{~B}^{2}
$$

The sign and magnitude of main effect signify the relative influence of each factor on the response. A negative sign signifies an antagonist effect while a positive sign indicates a synergistic effect.

Table $1 \mathrm{~b}$ shows the result of ANOVA test, which indicates that the developed model for the response was significant and adequate,

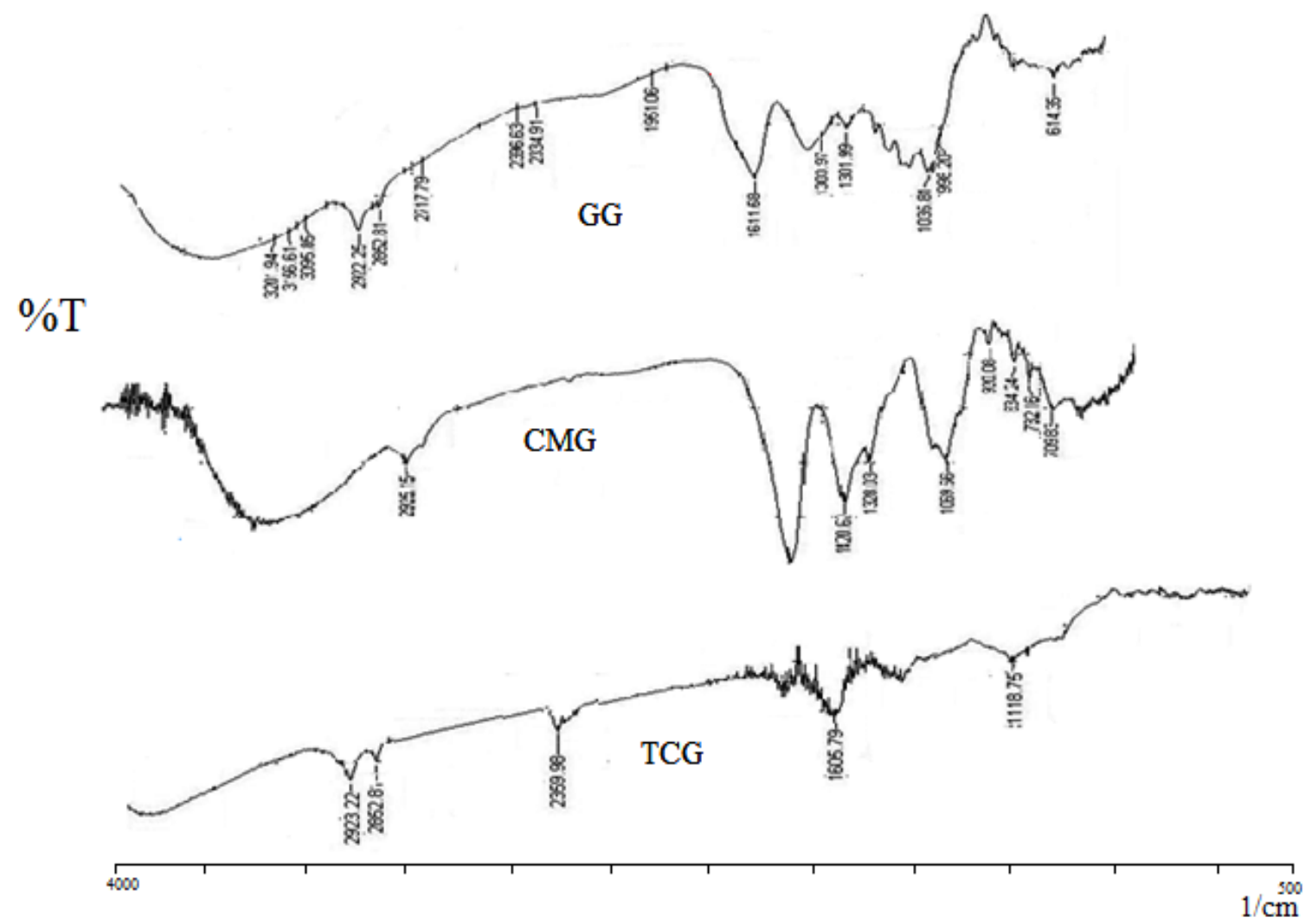

Figure 1. FT-IR spectra of GG, CMG and TCG. 


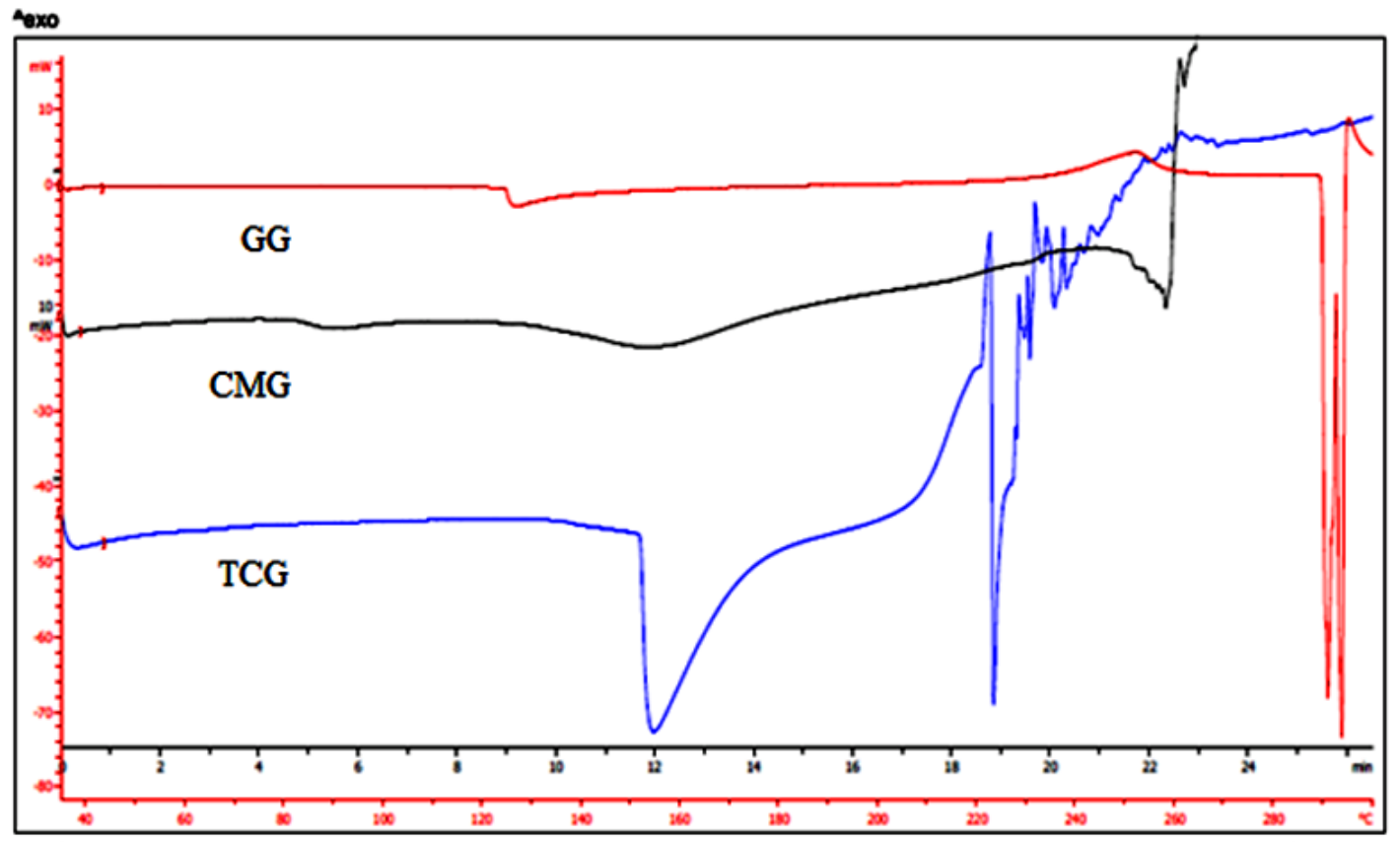

Lab: METTLER

STAR' SW 10.00

Figure 2. DSC thermograms of GG, CMG, and TCG.
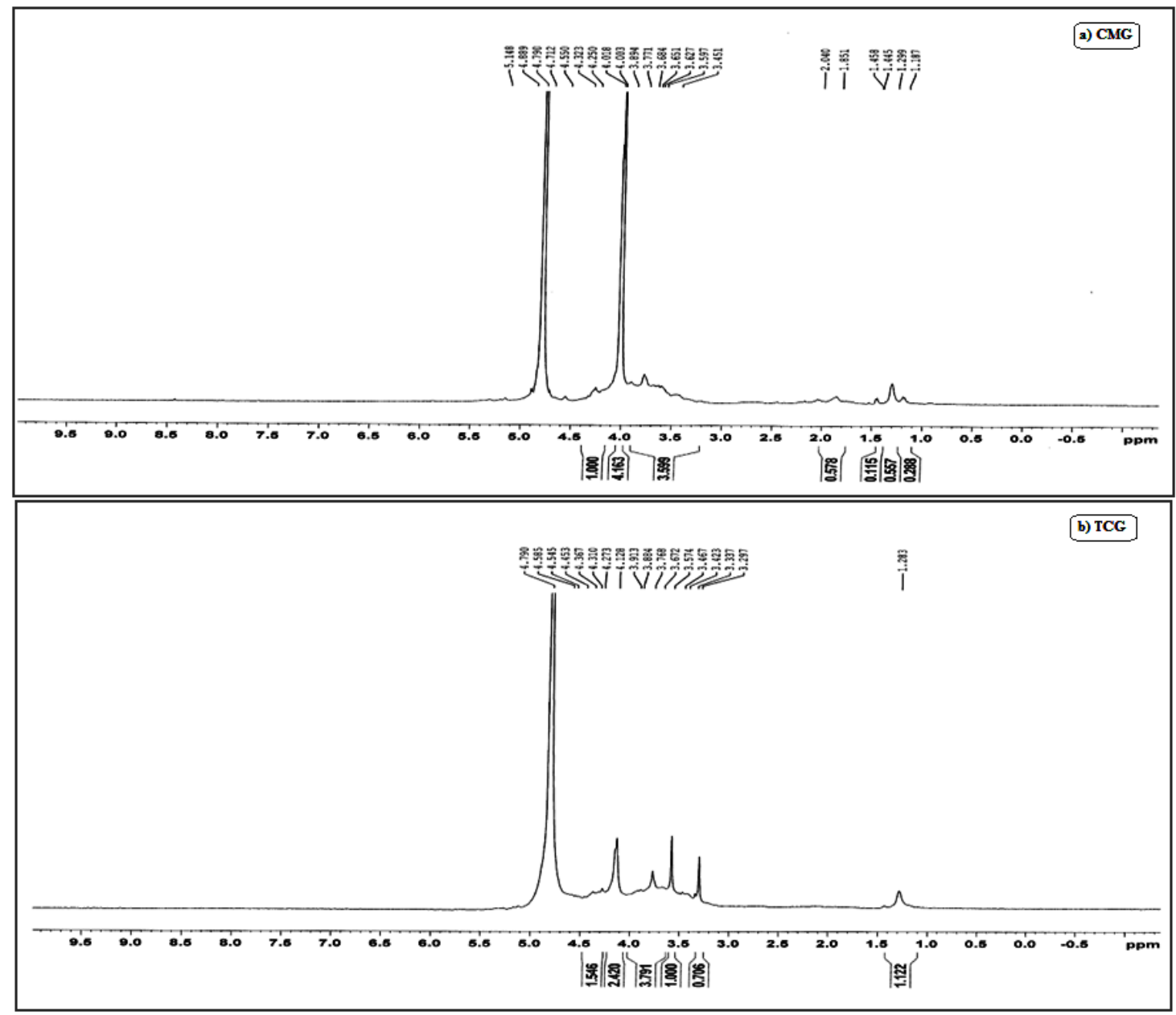

Figure 3 .NMR spectra of GG (a), CMG (b) and TCG (c). 
without significant lack of fit. The results of model summary statistics show the $\mathrm{R}^{2}$ value $>0.9$, for the response models, which indicate a good correlation between the experimental and predicted responses. Further, the higher values ( $>4)$ of "Adequate Precision" indicate adequate signals. The relatively lower value of coefficient of variation $(8.73 \%)$ indicates better precision and reliability of the experiments.

Table 1c represents the results of factor effects and associated $\mathrm{p}$-values for response $\mathrm{Y}$. The data reveals that significant factors affecting the response $\mathrm{Y}$ were the synergistic effects of linear contribution of $\mathrm{A}$ and $\mathrm{B}$, while the quadratic contribution of $\mathrm{A}^{2}$ and $\mathrm{B}^{2}$ antagonistically affected $\mathrm{Y}$.

Figure 4 depicts the 3-D response surface plots constructed using the models generated by response surface methodology. It shows the combined effect of concentrations of MCA and water:IPA ratio on the DS. From the plot it can be observed that water: IPA ratio has more pronounced effect on DS than the concentration of MCA. As the water: IPA ratio varies from 1:3 to 1:4 increases in DS but above ratio of 1:4, the DS decreases. The maximum DS was obtained at water:IPA ratio of $1: 4$, considered as optimal. It may be attributed to less swelling of GG in higher organic solvent concentration. This fact implies that solvent medium determines the extent of reaction [38,47-51].

In case of MCA concentration, response shows distinct pattern of the increase in DS by increasing the concentration of MCA which was optimal at $2 \mathrm{~g}$. However, a further increase in concentration of MCA beyond $2 \mathrm{~g}$ using the optimum dose of $\mathrm{NaOH}$ concentration favors the glycolate formation and the reaction efficiency decreases. Similar observations are reported for Cassia tora gum, starch, Leucaena glauca seed gum and Cassia occidentalis seed gum [51-53].

A numerical optimization technique using the desirability approach was employed to develop a new reaction with the desired response. The optimization was done with constraints for maximum DS (Y) as the goal was to locate the optimum setting of independent variables in the new reaction. The optimization tool provided us two sets of possible solutions. The optimal calculated parameters with highest desirability were 2g MCA and 1:4.14 water:IPA ratio. Using these parameters a batch of CMG was synthesized, which had the DS (Y) of 0.363 (predicted 0.371 ). The lower value of \% prediction error (for $\mathrm{Y}$ ) indicates the reliability of developed mathematical models.

\section{Viscosity}

The study was designed to accessed the aqueous behavior of polymer and difference between rheological behavior of GG and CMG depicted in Figure 5. The rheological behavior of aqueous solutions of GG $(0.5 \% \mathrm{w} / \mathrm{v})$ and $\mathrm{CMG}(0.5 \% \mathrm{w} / \mathrm{v})$ was assessed using viscometer.

Table 1b. Model summary statistics.

\begin{tabular}{|c|c|c|c|c|c|c|}
\hline $\begin{array}{c}\text { Response } \\
\text { factor }\end{array}$ & \multicolumn{5}{|c|}{ Model } \\
\hline \multirow{2}{*}{ DS } & F - Value & Prob $>$ F & $\mathbf{R}^{2}$ & Pred. $\mathbf{R}^{2}$ & $\begin{array}{c}\text { Adequate } \\
\text { precision }\end{array}$ & C.V. \% \\
\cline { 2 - 7 } & 9.55 & 0.0462 & 0.9409 & 0.3262 & 10.159 & 8.73 \\
\hline
\end{tabular}

Table 1c. Summary of each factor effect and its P-value.

\begin{tabular}{|c|c|c|}
\hline \multirow{2}{*}{ Factor } & \multicolumn{2}{|c|}{ Y } \\
\cline { 2 - 3 } & Factor effect & P-value \\
\hline A & +0.042 & 0.0260 \\
\hline B & +0.039 & 0.0315 \\
\hline $\mathbf{A}^{\mathbf{2}}$ & -0.021 & 0.1982 \\
\hline $\mathbf{B}^{\mathbf{2}}$ & -0.012 & 0.5387 \\
\hline & -0.064 & 0.0365 \\
\hline
\end{tabular}

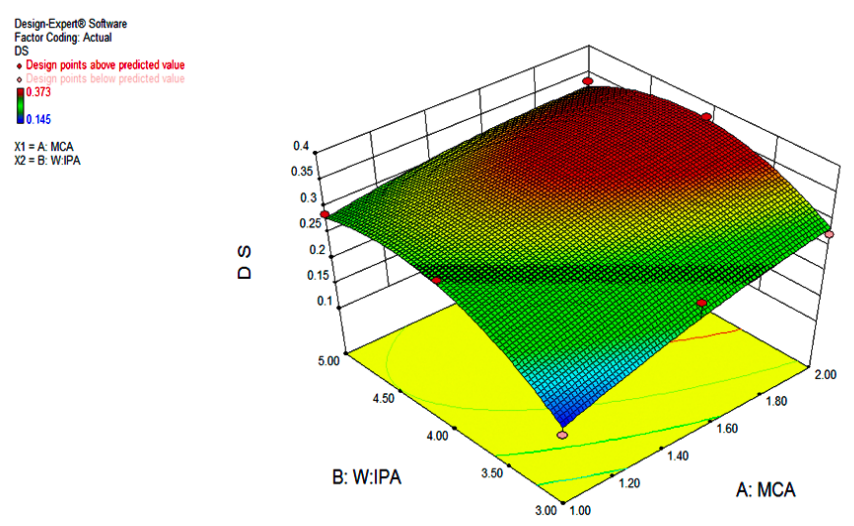

Figure 4. Response surface graph shows the combined effect of concentrations of MCA (g) and ratio of water and isopropyl alcohol.

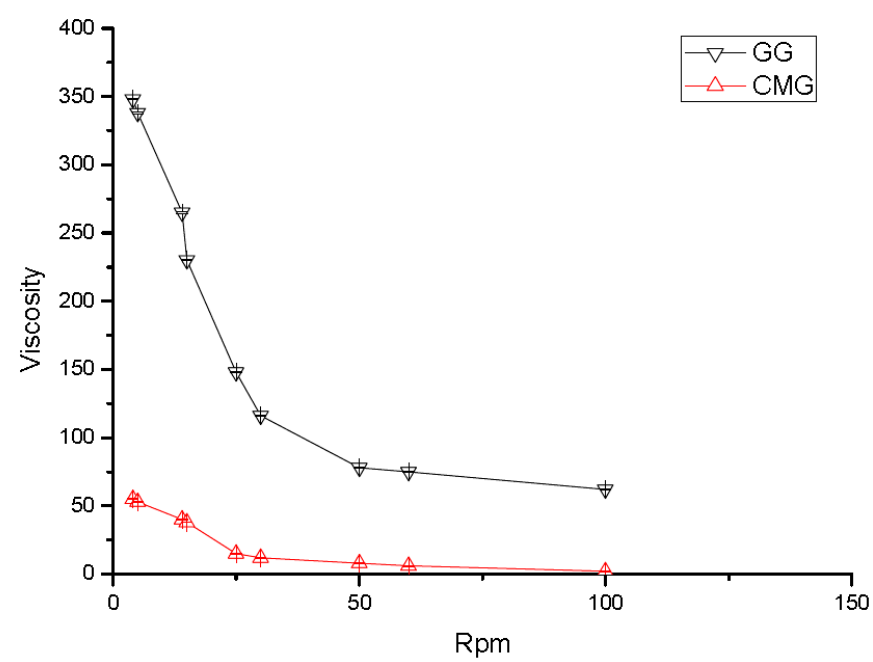

Figure 5. Rheological behaviors of aqueous solutions of GG and CMG.

From the results, it is evident that the aqueous solution of GG and CMG shows pseudo plastic flow behavior. The results further revealed that on carboxymethylation of GG, its viscosity falls considerably which is in accordance with previously reported literature related to carbamoylethylation of guar gum and carboxymethylation of xanthan gum [30,54]. GG imparts anionic character to its backbone chains, which due to columbic repulsion prevents the entanglement of backbone chains resulting in fall of their viscosity.

\section{Determination of thiol group content}

$$
\begin{aligned}
& \% S H=\frac{(10-3) \times 0.1 \times 33.07 \times 100}{2 g \times 1000} \\
& \% S H=\frac{2314.9}{2000}
\end{aligned}
$$

$\% \mathrm{SH}=1.15745$

So, it concludes that $0.58 \%$ thiol group content in $1 \mathrm{~g}$ of polymer.

\section{Swelling and gel fraction studies}

The CMG7 batch shows a highest swelling ratio compared to other CMG batches and GG (Table 2). The carboxymethylation of polymers trust on maximizing the degree of substitution, and even so the water 
solubility of carboxymethylated polymers increases with increasing substitution, which, in turn reduces the gelling properties [55].

\section{Evaluation of mucoadhesive strength and mechanical parameters of tablet}

The mucoadhesive strength of polymer compacts of GG and TCG was evaluated. The maximum adhesive force for GG and TCG compacts on goat intestinal mucosa was found to be $15 \mathrm{~g}$ and $56 \mathrm{~g}$ respectively. Thus, TCG demonstrated the 3.73 fold greater mucoadhesive strength than that of GG (Figure 6).

\section{Swelling behavior}

The swelling behavior of mucoadhesive polymers greatly influences their adhesive, cohesiveness, and drug release properties. With the absorbing, swelling, and capillary effects, mucoadhesive polymers should take water from the underlying mucosal tissue, which leads to considerably strong adhesion $[56,57]$.

The rate of swelling of TCG was higher as compared to GG (Figure 7). The GG tablet disintegrated and eroded within $10 \mathrm{~min}$, whereas tablet comprising TCG exhibited almost constant water uptake over $1.5 \mathrm{~h}$.

\section{Disintegration studies}

Disintegration studies of GG and TCG tablets were carried out. Disintegration study is a good indicator for cohesive properties of polymers. If polymer has a low degree of cohesiveness then the adhesive bond will form between polymer and the mucus layer interface rather than within the polymer itself. This study revealed that GG disintegrates within the 10 min compared to TCG, which was stable for $90 \mathrm{~min}$; it indicates that TCG shows more stability as compared to GG by the formation of disulfide bonds within the thiolated polymer (Figure 8).

\section{Conclusion}

In present investigation, the DS of CMG was optimized by response surface method using general factorial design. The concentration of MCA and the ratio of water: IPA was observed to exert more pronounced effect on DS. The covalent attachment of thiol group with esterification

Table 2. Swelling and gel fraction studies of GG and CMG.

\begin{tabular}{|c|c|c|c|}
\hline Batch & DS & Swelling Ratio & Gel Fraction (\%) \\
\hline $\mathbf{G G}$ & - & 1.26 & 99.73 \\
\hline $\mathbf{C M G}_{\mathbf{1}}$ & 0.87 & 3.84 & 61.34 \\
\hline $\mathbf{C M G}_{\mathbf{2}}$ & 0.62 & 3.15 & 62.28 \\
\hline $\mathbf{C M G}_{\mathbf{3}}$ & 0.83 & 3.79 & 60.78 \\
\hline $\mathbf{C M G}_{\mathbf{4}}$ & 0.97 & 3.99 & 59.13 \\
\hline $\mathbf{C M G}_{\mathbf{5}}$ & 0.76 & 3.70 & 61.95 \\
\hline $\mathbf{C M G}_{\mathbf{6}}$ & 0.41 & 2.98 & 66.64 \\
\hline $\mathbf{C M G}_{\mathbf{7}}$ & 1.12 & 5.17 & 50.35 \\
\hline $\mathbf{C M G}_{\mathbf{8}}$ & 0.94 & 3.91 & 60.15 \\
\hline $\mathbf{C M G}_{\mathbf{9}}$ & 0.53 & 2.86 & 69.28 \\
\hline $\mathbf{O C M G}$ & $\mathbf{0 . 3 6 3}$ & $\mathbf{4 . 9 5}$ & $\mathbf{5 7 . 2 1}$ \\
\hline
\end{tabular}

**Note: OCMG - Optimized batch

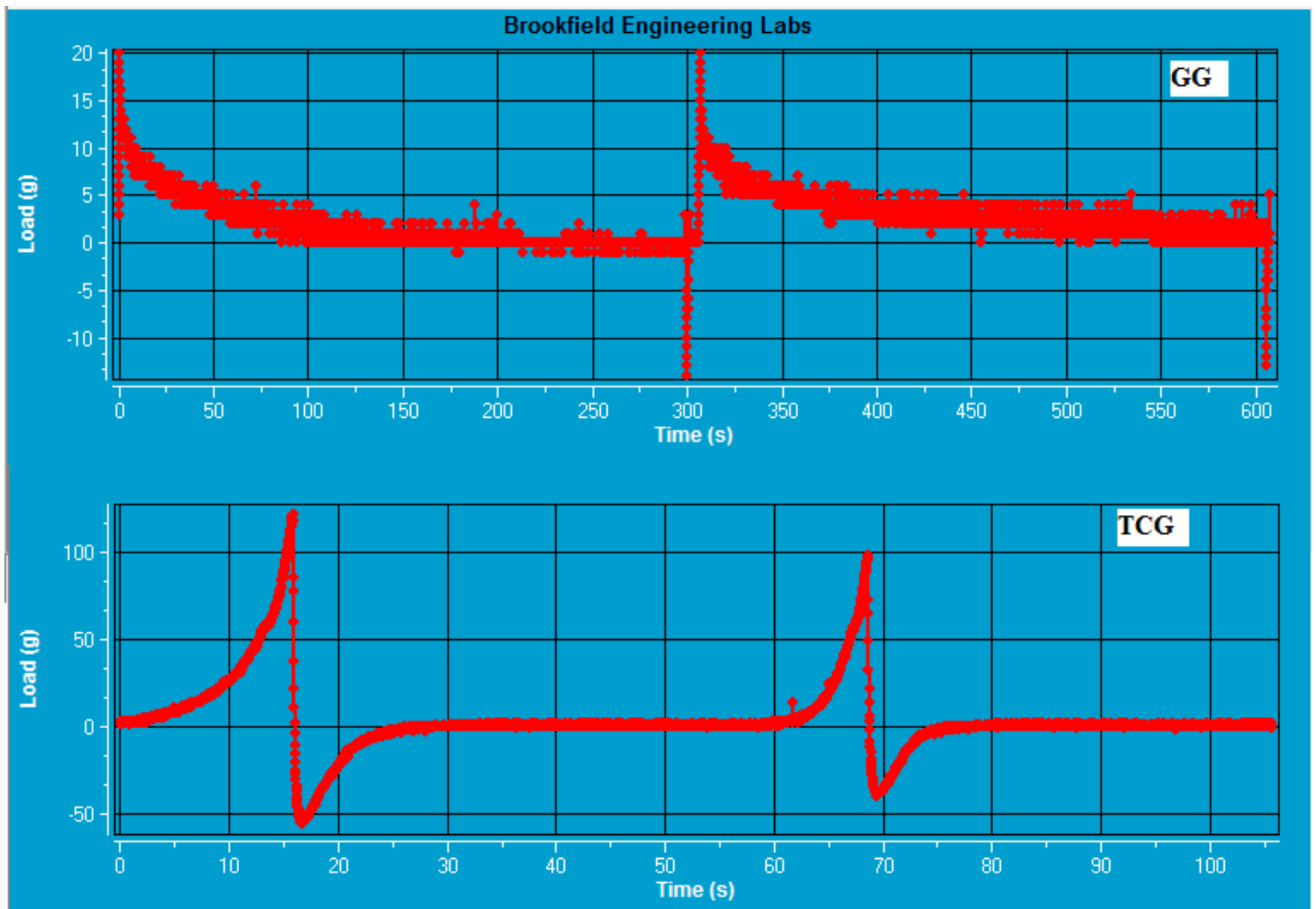

Figure 6. Tensile test profiles of GG and TCG polymer compacts. 


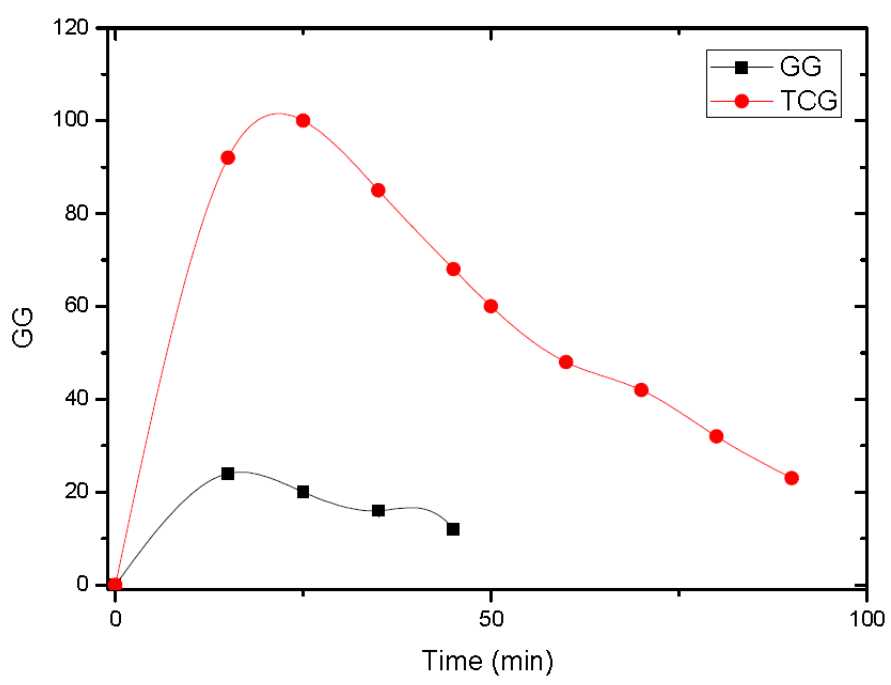

Figure 7. Comparisons of the water binding capacity of tablets containing gellan gum and its Conjugate with TCG in $100 \mathrm{mM}$ phosphate buffer solution $\mathrm{pH} 6.8$ at $37^{\circ} \mathrm{C}$.

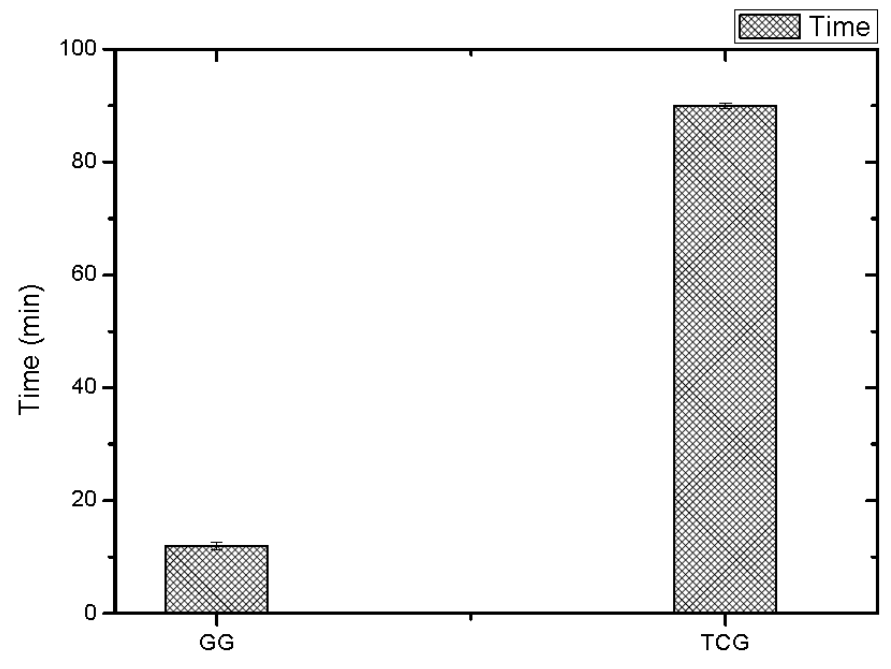

Sample Name

Figure 8. Comparisons of the disintegration time of tablets containing GG and its conjugate with TCG. Studies were carried out with a disintegration test apparatus (USP) in $100 \mathrm{mM}$ phosphate buffer solution $\mathrm{pH} 6.8$ at $37^{\circ} \mathrm{C}$.

to $\mathrm{CMG}$ leads to strongly improved mucoadhesive properties of polymer. Due to this chemical modification, swelling behavior and mucoadhesive potential of thiolated polymers can be improved. These properties of TCG might be useful for stability and adhesiveness on various mucosal tissues compared to well-established polymer.

\section{References}

1. Kast CE, Bernkop-Schnürch A (2001) Thiolated polymers-thiomers: development and in vitro evaluation of chitosan-thioglycolic acid conjugates. Biomaterials 22 : 2345-2352.

2. Iqbal J, Shahnaz G, Perera G, Hintzen F, Sarti F, et al. (2012) Thiolated chitosan: development and in vivo evaluation of an oral delivery system for leuprolide. Eur $J$ Pharm Biopharm 80: 95-102. [Crossref]

3. Bernkop-Schnürch A, Schwarz V, Steininger S (1999) Polymers with thiol groups: a new generation of mucoadhesive polymers? Pharm Res 16: 876-881. [Crossref]

4. Snyder GH, Reddy MK, Cennerazzo MJ, Field D (1983) Use of local electrostatic environments of cysteines to enhance formation of a desired species in a reversible disulfide exchange reaction. BBA-Protein Struct M 749: 219-226.
5. Bernkop-Schnurch, A. Mucoadhesive Polymers in Polymeric Biomaterials. Severian Dumitriu (Editor). New York. Marcell Dekker Inc. 2002. 147-162.

6. Bernkop-Schnürch A, Hornof M, Zoidl T (2003) Thiolated polymers-thiomers: synthesis and in vitro evaluation of chitosan-2-iminothiolane conjugates. Int J Pharm 260: $229-237$.

7. Krauland AH, Leitner VM, Bernkop-Schnürch A (2003) Improvement in the in situ gelling properties of deacetylated gellan gum by the immobilization of thiol groups. Journal of Pharmaceutical Sciences 92: 1234-1241.

8. Marschütz MK, Bernkop-Schnürch A (2002) Thiolated polymers: self-crosslinking properties of thiolated $450 \mathrm{kDa}$ poly(acrylic acid) and their influence on mucoadhesion. Eur J Pharm Sci 15: 387-394. [Crossref]

9. Bernkop-Schnürch A, Kast CE, Richter MF (2001) Improvement in the mucoadhesive properties of alginate by the covalent attachment of cysteine. $J$ Controlled Release 71 : 277-285.

10. Perera G, Hombach J, Bernkop-Schnürch A (2010) Hydrophobic thiolation of pectin with 4-aminothiophenol: synthesis and in vitro characterization. Aaps Pharmscitech 11: $174-180$.

11. Sharma R, Ahuja M (2011) Thiolated pectin: Synthesis, characterization and evaluation as a mucoadhesive polymer. Carbohyd Polym 85: 658-663.

12. Prajapati VD, Jani GK, Zala BS, Khutliwala TA (2013) An insight into the emerging exopolysaccharide gellan gum as a novel polymer. Carbohyd Polym 93: 670-678.

13. Banik RM, Kanari B, Upadhyay SN (2000) Exopolysaccharide of the gellan family: prospects and potential. World J Microb Biot 16: 407-414.

14. Lapasin R, Pricl S (1995) Rheology. In Rheology of industrial polysaccharides: Theory and applications. Springer US, pp: 162-249.

15. Kuo MS, Mort AJ, Dell A (1986) Identification and location of L-glycerate, an unusual acyl substituent in gellan gum. Carbohydrate Research 156: 173-187.

16. García MC, Alfaro MC, Calero N, Muñoz J (2011) Influence of gellan gum concentration on the dynamic viscoelasticity and transient flow of fluid gels. Biochem Eng J 55: 73-81.

17. Paul F, Morin A, Monsan P (1986) Microbial polysaccharides with actual potential industrial applications. Biotechnol Adv 4: 245-259.

18. Kubo W, Miyazaki S, Attwood D (2003) Oral sustained delivery of paracetamol from in situ-gelling gellan and sodium alginate formulations. Int J Pharm 258: 55-64. [Crossref]

19. Miyazaki S, Aoyama H, Kawasaki N, Kubo W, Attwood D (1999) In situ-gelling gellan formulations as vehicles for oral drug delivery. J Control Release 60: 287-295. [Crossref]

20. Kang KS, Veeder GT, Inventors; Merck \& Co., Inc., assignee (1982) Polysaccharide S-60 and bacterial fermentation process for its preparation. United States patent US $4,326,053$.

21. Grasdalen H, Smidsrød O (1987) Gelation of gellan gum. Carbohyd Polym 7: 371-393.

22. Miyamoto K, Tsuji K, Nakamura T, Tokita M, Komai T (1996) Preparation of carboxymethyl-gellan. Carbohyd Polym 30: 161-164.

23. Biswal DR, Singh RP (2004) Characterisation of carboxymethyl cellulose and polyacrylamide graft copolymer. Carbohyd Polym 57: 379-387.

24. Togrul H, Arslan N (2003) Production of carboxymethyl cellulose from sugar beet pulp cellulose and rheological behaviour of carboxymethyl cellulose. Carbohyd Polym 54: 73-82.

25. Stojanovic Z, Jeremic K, Jovanovic S (2000) Synthesis of carboxymethyl starch. Starch-starke 52: 413-419.

26. Tijsen CJ, Kolk HJ, Stamhuis EJ, Beenackers AA (2001) An experimental study on the carboxymethylation of granular potato starch in non-aqueous media. Carbohyd Polym 45: 219-226.

27. Abreu FR, Campana-Filho SP (2005) Preparation and characterization of carboxymethylchitosan. Polimeros 15: 79-83.

28. Parvathy KS, Susheelamma NS, Tharanathan RN, Gaonkar AK (2005) A simple nonaqueous method for carboxymethylation of galactomannans. Carbohyd Polym 62: 137-141.

29. Petzold K, Schwikal K, Heinze T (2006) Carboxymethyl xylan—synthesis and detailed structure characterization. Carbohyd Polym 64: 292-298.

30. Ahuja M, Kumar A, Singh K (2012) Synthesis, characterization and in vitro release behavior of carboxymethyl xanthan. Int J Biol Macromol 51: 1086-1090. [Crossref] 
31. Kumar A, Ahuja M (2012) Carboxymethyl gum kondagogu: synthesis, characterization and evaluation as mucoadhesive polymer. Carbohyd Polym 90: 637-643.

32. Silva DA, de Paula RC, Feitosa JP, de Brito AC, Maciel JS, et al. (2004) Carboxymethylation of cashew tree exudate polysaccharide. Carbohyd Polym 58: 163171.

33. Goh TN (2001) A pragmatic approach to experimental design in industry. J Appl Stat 28: 391-398.

34. Hamsaveni DR, Prapulla SG, Divakar S (2001) Response surface methodological approach for the synthesis of isobutyl isobutyrate. Process Biochem 36: 1103-1109.

35. Soo EL, Salleh AB, Basri M, Rahman RA, Kamaruddin K (2004) Response surface methodological study on lipase-catalyzed synthesis of amino acid surfactants. Process Biochem 39: 1511-1518.

36. dos Santos KS, Silva HS, Ferreira EI, Bruns RE (2005) $3^{2}$ Factorial design and response surface analysis optimization of N-carboxybutylchitosan synthesis. Carbohyd Polym 59: $37-42$.

37. Huijbrechts AM, Vermonden T, Bogaert P, Franssen MC, Visser GM, et al. (2009) Optimization of the synthesis of 1-allyloxy-2-hydroxy-propyl-starch through statistical experimental design. Carbohyd Polym 77: 25-31.

38. Chen XG, Park HJ (2003) Chemical characteristics of O-carboxymethyl chitosans related to the preparation conditions. Carbohyd Polym 53: 355-359.

39. Dicharry RM, Ye P, Saha G, Waxman E, Asandei AD, et al. (2006) Wheat GlutenThiolated Poly (vinyl alcohol) Blends with Improved Mechanical Properties. Biomacromolecules 7: 2837-2844.

40. Stojanovic Ž, Jeremic K, Jovanovic S, Lechner MD (2005) A comparison of some methods for the determination of the degree of substitution of carboxymethyl starch. Starch-Stärke 57: 79-83.

41. Vogel AI (1958) Elementary practical organic chemistry. (2 ${ }^{\text {nd }}$ edn) PART III Quantitative Organic Analysis, Longmans, Green; 1958, Longman Group Limited, London, (chapter-xxxv).

42. Onuki Y, Hoshi M, Okabe H, Fujikawa M, Morishita M, et al. (2005) Formulation optimization of photocrosslinked polyacrylic acid modified with 2-hydroxyethyl methacrylate hydrogel as an adhesive for a dermatological patch. $J$ Control Release 108: $331-340$
43. Kaur H, Yadav S, Ahuja M, Dilbaghi N (2012) Synthesis, characterization and evaluation of thiolated tamarind seed polysaccharide as a mucoadhesive polymer. Carbohyd Polym 90: 1543-1549.

44. Lawal OS, Lechner MD, Hartmann B, Kulicke WM (2007) Carboxymethyl cocoyam starch: synthesis, characterisation and influence of reaction parameters. Starch-Stärke 59: 224-233.

45. Tijsen CJ, Scherpenkate HJ, Stamhuis EJ, Beenackers AA (1999) Optimisation of the process conditions for the modification of starch. Chem Eng Sci 54: 2765-2772.

46. Silverstein RM, Webster FX, Kiemle DJ, Bryce DL (2014) Spectrometric identification of organic compounds. John wiley \& sons.

47. Bhattacharyya D, Singhal RS, Kulkarni PR (1995) Physicochemical properties of carboxymethyl starch prepared from corn and waxy amaranth starch. Carbohyd Polym 27: $167-169$.

48. Bhattacharyya D, Singhal RS, Kulkarni PR (1995) A comparative account of conditions for synthesis of sodium carboxymethyl starch from corn and amaranth starch. Carbohyd Polym 27: 247-253.

49. Khalil MI, Hashem A, Hebeish A (1990) Carboxymethylation of maize starch. StarchStärke 42: 60-63.

50. Goyal P, Kumar V, Sharma P (2007) Carboxymethylation of tamarind kernel powder. Carbohyd Polym 69: 251-255.

51. Gupta S, Sharma P, Soni PL (2004) Carboxymethylation of Cassia occidentalis seed gum. J Appl Polym Sci 94: 1606-1611.

52. Hebeish A, Khalil MI (1988) Chemical factors affecting preparation of carboxymethyl starch. Starch-Stärke 40: 147-150.

53. Sharma BR, Kumar V, Soni PL, Sharma P (2003) Carboxymethylation of Cassia tora gum. J Appl Polym Sci 89: 3216-319.

54. Sharma BR, Kumar V, Soni PL (2004) Carbamoylethylation of guar gum. Carbohyd Polym 58: 449-453.

55. Dodi G, Hritcu D, Popa MI (2011) Carboxymethylation of guar gum: Synthesis and characterization. Cell Chem Technol 45: 171.

56. Mortazavi SA, Smart JD (1993) An investigation into the role of water movement and mucus gel dehydration in mucoadhesion. J Control Release 25: 197-203.

57. Duchêne D, Ponchel G (1992) Principle and investigation of the bioadhesion mechanism of solid dosage forms. Biomaterials 13: 709-714. [Crossref]

Copyright: $(02017$ More MP. This is an open-access article distributed under the terms of the Creative Commons Attribution License, which permits unrestricted use, distribution, and reproduction in any medium, provided the original author and source are credited. 